\title{
Mechanical Properties Improvement Evaluation of Medium Carbon Steels Quenched in Different Media
}

\author{
Ikubanni, Peter Pelumi ${ }^{1, a^{*}}$, Adediran, Adeolu Adesoji $i^{2, b}$, \\ Adeleke, Adekunle Akanni ${ }^{3, c}$, Ajao, Kajogbola Rasaq ${ }^{4, d}$ \\ and Agboola, Olayinka Oluwole ${ }^{5, \mathrm{e}}$ \\ ${ }^{1,2,5}$ Department of Mechanical Engineering, Landmark University, Omu-Aran, Kwara State, Nigeria \\ ${ }^{3,4}$ Department of Mechanical Engineering, University of Ilorin, Ilorin, Kwara State, Nigeria \\ aikubanni.peter@Imu.edu.ng, ’adediran.adeolu@Imu.edu.ng, ${ }^{c}$ adeleke.kunle@ymail.com, \\ dajaomech@unilorin.edu.ng, eagboola.olayinka@Imu.edu.ng
}

Keywords: Improvement, Mechanical, tensile strength, hardness value, quenched, properties

\begin{abstract}
The effect of quenching on the mechanical properties of medium carbon steels using coconut (CW) water, pap water (PW) and spent engine oil (SPE) which have been largely considered as wastes was investigated. All specimens were normalized at a temperature of $840^{\circ} \mathrm{C}$ in order to remove residual stresses induced during machining operations. Various specimens were heated to ranges of $730-790^{\circ} \mathrm{C}$ and soaked for the range of $30-60$ minutes respectively. Brinnel hardness tester was used to obtain the hardness values while Testometric M500-50AT model machine was used for the tensile test of the specimens. The highest hardness value (609.97 BHN) was obtained from the specimen heated to $790^{\circ} \mathrm{C}$ quenched in pap water as compared with 166.4 BHN for the normalized as-received sample. The yield (YS) and ultimate tensile (UTS) strengths of the quenched specimens were better than the normalized as-received sample. SPEquenched samples yielded the highest YS and UTS combined. The hardness value increased while YS and UTS decreased with soaking time for different temperatures. The highest hardness value for the specimens was obtained from coconut and pap water. Rather than been considered as wastes, coconut water, pap water and spent engine oil can improve the mechanical properties of medium carbon steel when used as quenching media.
\end{abstract}

\section{Introduction}

Steel is still one of the most important engineering materials in use today for structural works regardless of vehement competition for other purposes [1]. Steel has found extensive use in virtually every sphere of engineering works: building, bridges, construction, agriculture, military, automobile, power generation, telecommunications, aviation, drilling, exploration, health sector, oil and gas. The main application of steel in construction includes trusses and concrete reinforcement. In Nigeria, cases of structural failure have in recent time become a frequent report especially for buildings and many lives and properties have been lost in series of such disasters [2, 3]. A good numbers of researchers $[4,5,6,7,8]$ have conducted investigations into the causes of building collapses and one of the most frequently adduced causes is that the structural properties of the materials used in the actual constructions do not conform with standards. As a measure to avert further loss of lives and properties as a result of structural failure, it is therefore pertinent to seek improvement on the properties of local steel bars used for construction purposes. Heat treatment of steel bar have been reported to improve its quality and therefore the present study is aimed at improving the mechanical properties of some selected local steel bars using quenching medium that have been largely considered to be waste. Quenching is one of the important processes of the heat treatment to improve the performance of steel. Quenching is performed to prevent ferrite or pearlite formation and allow bainite or martensite to be formed. The most common quenching media used include oil that contains a variety of additives, water and aqueous polymer solution. Odusote et al. [9] used water and palm oil to quench medium carbon steel at different temperatures and soaking time of 45 minutes. They observed a higher tensile strength and hardness than the as-received 
samples. Dauda et al. [10] also worked on the effect of various quenching media (palm kernel oil, cotton seed oil and olive oil) on mechanical properties of annealed $0.509 \% \mathrm{wtC}-0.178 \% \mathrm{Mn}$ steel and recommended that olive oil can be used where cooling severity less than water and SAE 40 engine oil is required for hardening of plain carbon steel. The mechanical properties of dual phase steel quenched in bitumen were also studied by Adediran et al. [11]. In their work, samples subjected to $790^{\circ} \mathrm{C}$ soaked for 45 mins and quenched in bitumen possessed relatively the best combination of tensile properties, hardness and impact energy. The media used by these previous researchers has enough competitive usage apart from being used as quenchants; therefore, the present study focuses on coconut water, pap water and spent engine oil as quenching media for improving the mechanical properties of medium carbon steel.

\section{Materials and Method}

The materials used in this research include medium carbon steel (with chemical composition shown in Table 1) and quenching media which include coconut water $(\mathrm{CW})$, pap water (PW) and spent engine oil (SPE). The chemical composition of medium carbon steel samples used for the present study as obtained from optical emission spectrophotometer is given in Table 1.

Table 1: Chemical composition of the medium carbon steel.

\begin{tabular}{|c|l|l|l|l|l|l|l|}
\hline $\mathrm{C}$ & $\mathrm{Si}$ & $\mathrm{Mn}$ & $\mathrm{S}$ & $\mathrm{Cr}$ & $\mathrm{Ni}$ & $\mathrm{Cu}$ & $\mathrm{Fe}$ \\
\hline 0.389 & 0.182 & 0.980 & 0.030 & 0.111 & 0.135 & 0.368 & 97.805 \\
\hline
\end{tabular}

\section{Specimen preparation}

Various specimens from the same medium carbon steel were prepared for the hardness (Figure 1). Tensile test specimens were also produced according to BSI standards [12] using a medium size lathe machine (Figure 2).

\section{Heat treatment and Quenching}

The prepared samples were first heat-treated in a muffle furnace to temperature of $840^{\circ} \mathrm{C}$ and normalized in order to reduce the stresses that might have been induced during machining operations. This was also done for structural and metallurgical readjustment, re-conditioning of the phases and induction of homogeneous structure in the samples. The prepared samples were later heated to $730^{\circ} \mathrm{C}, 760^{\circ} \mathrm{C}$ and $790^{\circ} \mathrm{C}$ and soaked for 30,45 and 60 minutes respectively using a muffle furnace. After each heat treatment temperature have been reached, the samples were quickly removed from the furnace and quenched in the different media; which were coconut water, pap water and spent engine oil. However, the control sample was only heated to $840^{\circ} \mathrm{C}$ and normalized.

\section{Mechanical Tests}

Hardness testing: Metallic Brinell hardness tester was used in the determination of the hardness of the different quenched samples together with the control sample. The specimens as shown in Figure 1 were brought in contact with the ball indenter having direct load of $500 \mathrm{~N}$ for 15 seconds dwelling time. After this, the ball indenter was disengaged from the samples and indented portion was read out. The Brinell's hardness value for each sample was calculated using Equation 1. The hardness tests were carried out in triplicates on each sample and its average value was recorded.

$$
\mathrm{BHN}=\frac{2 F}{\pi D\left(D-\sqrt{D^{2}-d^{2}}\right)}
$$

$$
\begin{aligned}
& \text { Where } \mathrm{F}=\text { Force }(\mathrm{N}) \\
& \qquad \begin{array}{l}
\mathrm{D}=\text { diameter of the ball }(\mathrm{mm}) \\
\mathrm{d}=\text { Average diameter of the indentation }(\mathrm{mm})
\end{array}
\end{aligned}
$$


Tensile testing: A Testometric M500-50AT model machine was used for the tensile test. Each of the specimens as shown in Figure 2 was loaded until fracture. The initial gauge length for each sample was noted before the application of the load. After which the machine generated graphs of the various samples. The yield and tensile strength and the percentage elongation of the each sample were determined from the data generated.

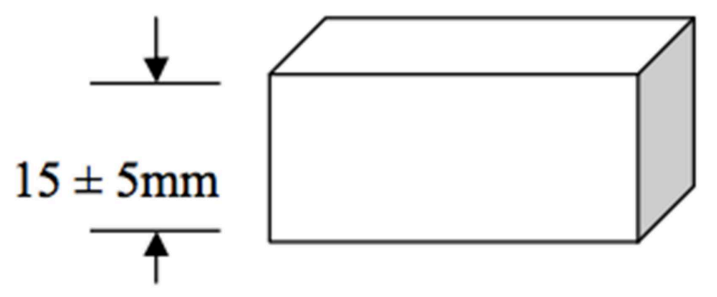

Fig. 1: Hardness test specimen.
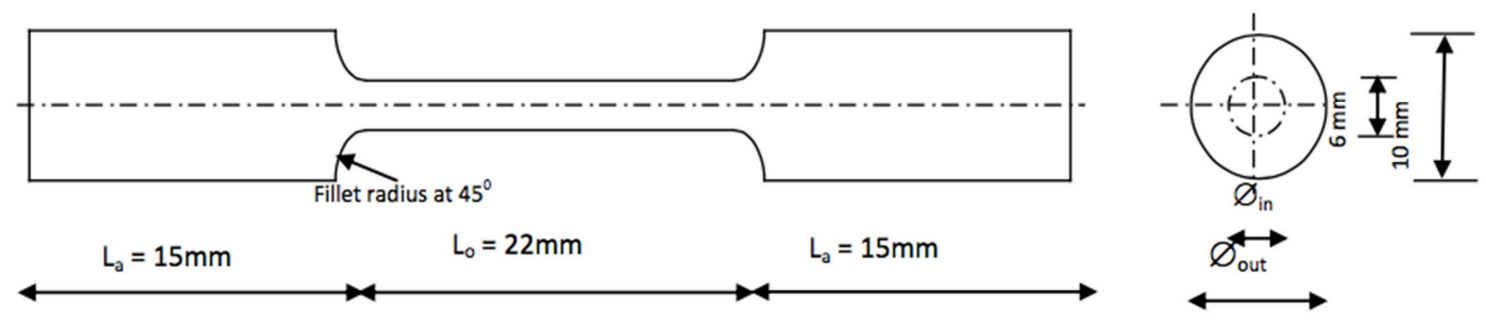

Fig. 2: Tensile test specimen.

\section{Results and Discussion}

The hardness values, yield and ultimate tensile strengths for the specimens in different media are presented in Tables 2 - 4. Tables 2 - 4 also show variations of heating temperatures (HT) and soaking times (ST).

Table 2: Properties of sample quenched in coconut water.

\begin{tabular}{|cccccc|}
\hline S/N & HT $\left({ }^{\circ} \mathrm{C}\right)$ & ST $(\min )$ & Hardness $(\mathrm{BHN})$ & YS(Mpa $)$ & UTS(MPa) \\
\hline 0 & control & - & 166.40 & 162.9 & 171.1 \\
1 & 730 & 30 & 349.19 & 220.0 & 252.6 \\
2 & 760 & 30 & 332.27 & 224.1 & 248.5 \\
3 & 790 & 30 & 332.27 & 468.5 & 499.0 \\
4 & 730 & 45 & 269.91 & 207.8 & 228.1 \\
5 & 760 & 45 & 609.97 & 264.8 & 268.8 \\
6 & 790 & 45 & 573.35 & 382.9 & 391.1 \\
7 & 730 & 60 & 499.23 & 89.6 & 93.7 \\
8 & 760 & 60 & 573.35 & 183.3 & 191.0 \\
9 & 790 & 60 & 573.35 & 358.5 & 399.2 \\
\hline
\end{tabular}

Table 3: Properties of sample quenched in pap water.

\begin{tabular}{|cccccc|}
\hline S/N & HT $\left({ }^{\circ} \mathrm{C}\right)$ & ST $(\min )$ & Hardness(BHN) & YS(Mpa) & UTS (MPa) \\
\hline 1 & 730 & 30 & 296.91 & 301.5 & 334.1 \\
2 & 760 & 30 & 499.23 & 224.1 & 248.5 \\
3 & 790 & 30 & 471.59 & 224.1 & 252.6 \\
4 & 730 & 45 & 349.19 & 116.1 & 138.5 \\
5 & 760 & 45 & 573.35 & 171.1 & 183.3 \\
6 & 790 & 45 & 609.97 & 268.9 & 317.8 \\
7 & 730 & 60 & 367.30 & 277.0 & 285.2 \\
8 & 760 & 60 & 532.37 & 407.4 & 427.8 \\
9 & 790 & 60 & 499.23 & 342.2 & 350.4 \\
\hline
\end{tabular}


Table 4: Properties of sample quenched in spent engine oil.

\begin{tabular}{|cccccc|}
\hline S/N & HT $\left({ }^{\circ} \mathrm{C}\right)$ & ST $(\mathrm{min})$ & Hardness(BHN) & YS(Mpa) & UTS(MPa) \\
\hline 1 & 730 & 30 & 210.61 & 529.6 & 539.8 \\
2 & 760 & 30 & 243.48 & 236.3 & 277.0 \\
3 & 790 & 30 & 283.30 & 382.9 & 415.5 \\
4 & 730 & 45 & 219.85 & 158.9 & 175.2 \\
5 & 760 & 45 & 440.37 & 309.6 & 342.2 \\
6 & 790 & 45 & 311.41 & 317.8 & 342.2 \\
7 & 730 & 60 & 332.27 & 342.2 & 399.2 \\
8 & 760 & 60 & 296.91 & 382.9 & 391.1 \\
9 & 790 & 60 & 393.52 & 301.5 & 325.9 \\
\hline
\end{tabular}

*HT-heating temperature, ST-soaking time, YS-yield strength, UTS-ultimate tensile strength.

Figures 3-5 illustrates the comparison between the media used on the hardness values of the samples. All samples quenched in different media used have higher hardness values as compared with the normalized as-received sample. Samples quenched in coconut (CW) and pap (PW) water at the soaking time of 45 and 60 minutes gave the highest hardness value of $609.97 \mathrm{BHN}$. The highest hardness value was obtained at quenching temperature of $760^{\circ} \mathrm{C}$ and $790^{\circ} \mathrm{C}$. The ranges of temperature used in the present study were less than that of Filippow et al. [13]. They used a temperature range of $800^{\circ} \mathrm{C}$ and $1200^{\circ} \mathrm{C}$ and observed that there was a drop in hardness as the quenching temperatures increases. Increase in temperature increases residual austenitic contents of the steel samples used in their study. Leonidov et al. [14] also studied the effect of quenching temperature on properties and structure of die steel and observed that an increase in quenching temperature caused a reduction in hardness. Therefore, the temperature ranges used for the present study is viable for quenching of medium carbon steel in terms of hardness. It was observed that the hardness values for the samples quenched in SPE were low as compared with CW and PW at different quenching temperatures and soaking time. This is similar to the observation of Vivek et al. [15] that water gives higher hardness values and the amount of martensitic phase that evolved in its usage are better than oil. Odusote et al. [9] also affirms that the fast cooling rate of water resulted in high free carbon in martensite, thus a better hardness than oil.

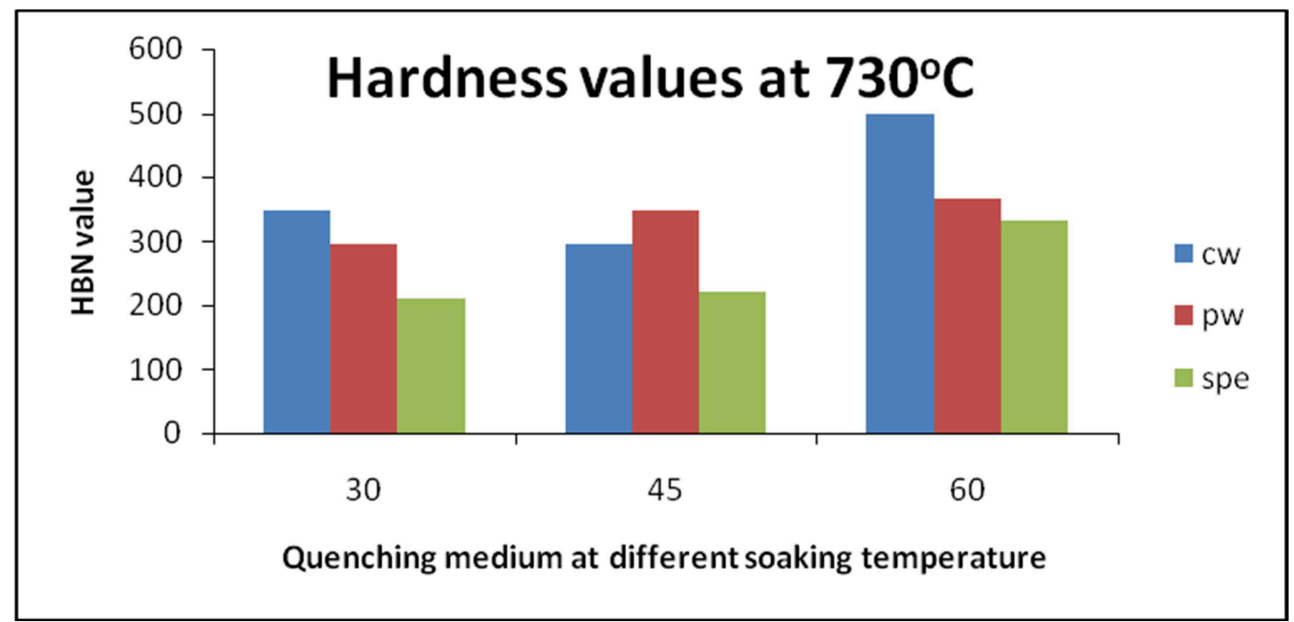

Fig. 3: Hardness values of samples heated to $730^{\circ} \mathrm{C}$ with different soaking temperatures. 


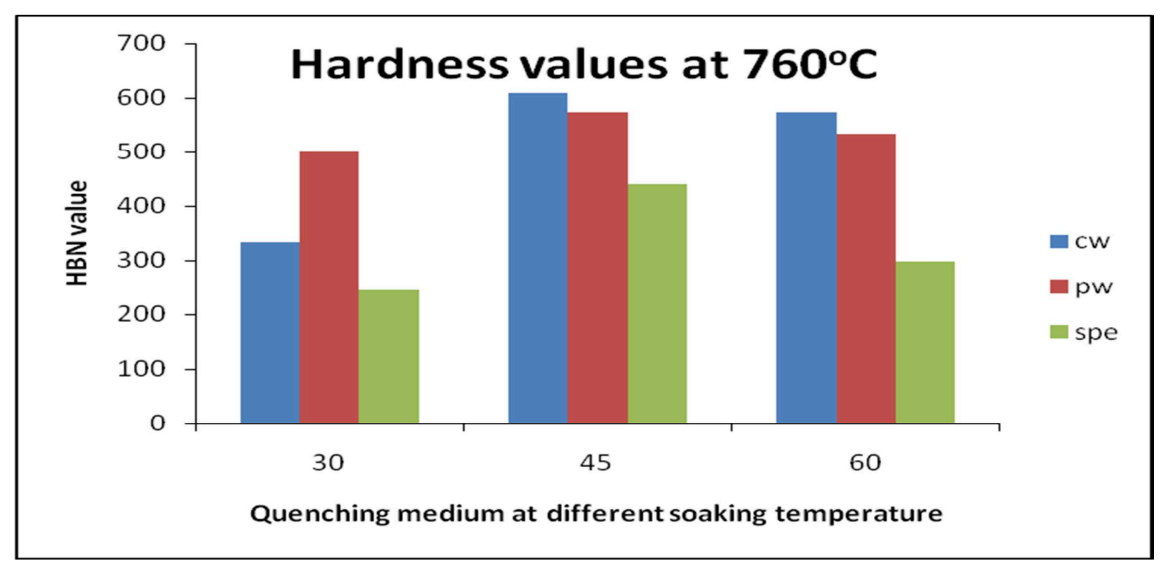

Fig. 4: Hardness values of samples heated to $760^{\circ} \mathrm{C}$ with different soaking temperatures.

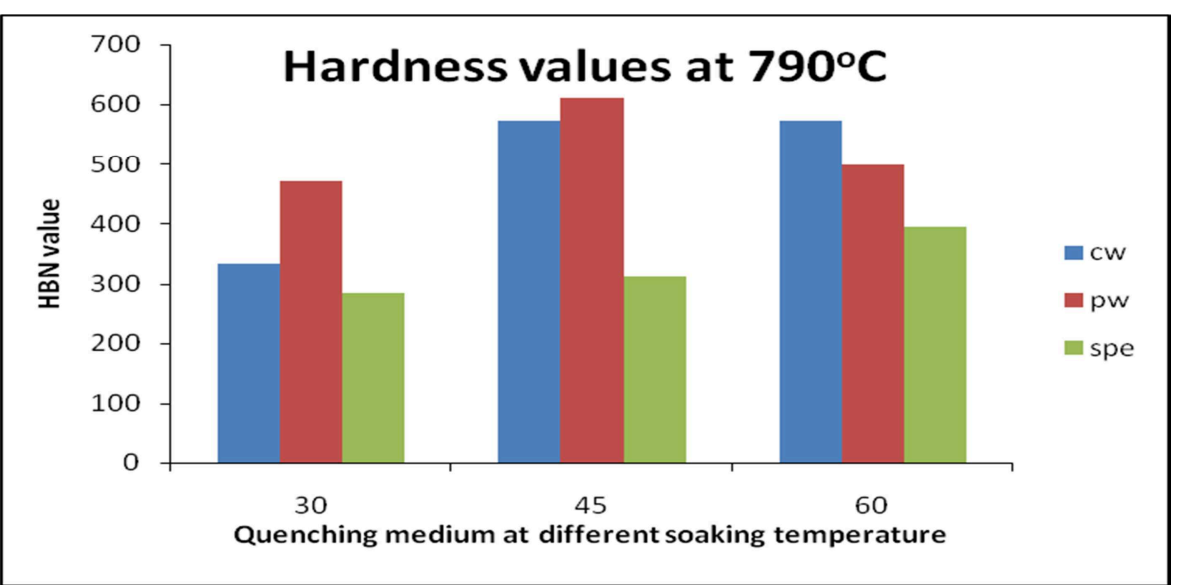

Fig. 5: Hardness values of samples heated to $790^{\circ} \mathrm{C}$ with different soaking temperatures.

The highest values of 468.5 MPa YS and 499.0MPa UTS were obtained for CW-quenched sample (HT: $790^{\circ} \mathrm{C}$, ST: 30 minutes). At $730^{\circ} \mathrm{C}$, ST of 60 minutes, $89.6 \mathrm{MPa}$ and $93.7 \mathrm{MPa}$ were the least values obtained for YS and UTS respectively (Figures 6-14). Apart from the two outliers, the other samples yielded a balanced combination of YS, UTS and hardness values. Similarly, samples quenched in PW yielded $407.4 \mathrm{MPa}$ and $427.8 \mathrm{MPa}$ for YS and UTS respectively at $760^{\circ} \mathrm{C} \mathrm{HT}$ (60 minutes ST). The lowest YS and UTS combined obtained for PW were $116.1 \mathrm{MPa}$ and 138.5 MPa respectively (Figures 6-14). For various HT and ST variations, PW-quenched samples were better than the normalized as-received samples in terms of YS and UTS. SPE-quenched samples had highest YS and UTS combined of 529.6MPa and 539.8MPa respectively. The lowest values of YS $(158.9 \mathrm{MPa})$ and UTS $(175.2 \mathrm{MPa})$ were obtained at $730^{\circ} \mathrm{C} \mathrm{HT}, 45 \mathrm{mintes}$ ST for SPE-quenched samples. Better YS and UTS obtained for SPE-quenched samples may be as a result of slow cooling rate of oil as compared with water [11, 16]. The least yield strength was obtained at $730^{\circ} \mathrm{C}$ at 60 minutes ST, which was even lesser than the normalized as-received sample. Samples quenched in SPE had the better YS and UTS combined values as this may be due to the less cooling severity of the medium. PW and CW quenched samples were exposed to high cooling rate due to the nature of water and thus may account for the low YS and UTS values as compared with SPE. In their work, effect of heat treatment (quenching) on the mechanical properties of reinforcing steel bars, Odusote et al. [17], stated a similar behavior in the response of water and palm oil during quenching. Cooling with $\mathrm{CW}$ and $\mathrm{HT}$ of $760^{\circ} \mathrm{C}$ for 60 minutes ST must be carefully avoided when heat treating a medium carbon steel for an improved mechanical properties. The three media used has improved the mechanical properties of the medium carbon steel samples. However, when hardness is a priority for the selection of material for any engineering purposes, it is recommended that CW and PW be employed but when strength and hardness becomes vital, SPE can be useful. High hardness value, yield and ultimate tensile strengths were obtained from the media used during the quenching process thus, improving the mechanical properties of the medium carbon steel samples. 


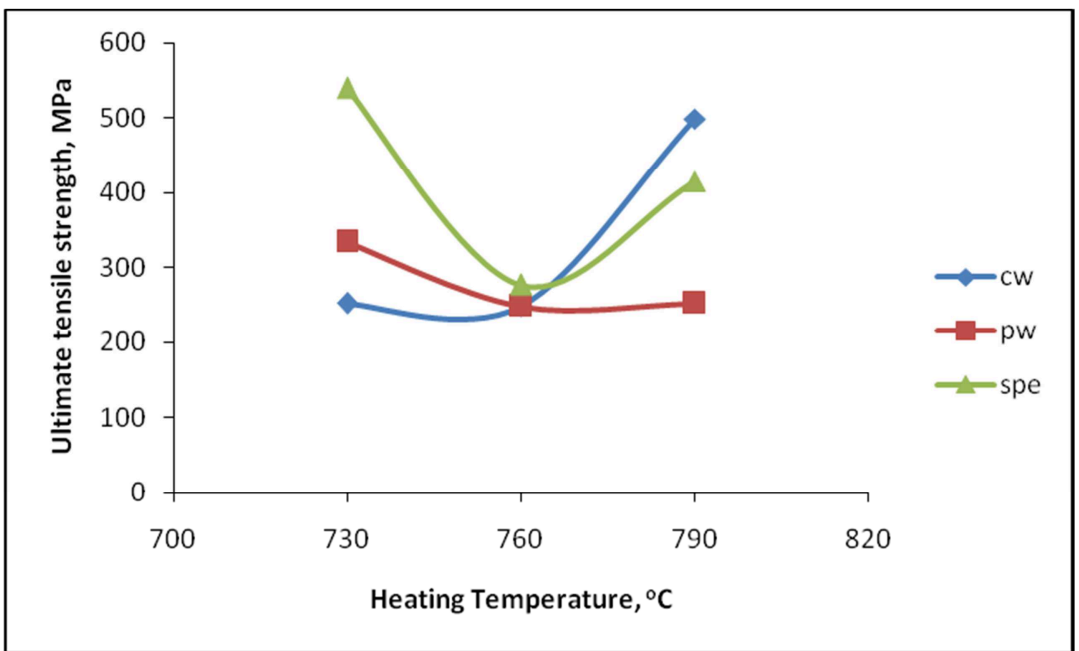

Fig. 6: Ultimate tensile strength against heating temperature at 30 mins soaking time.

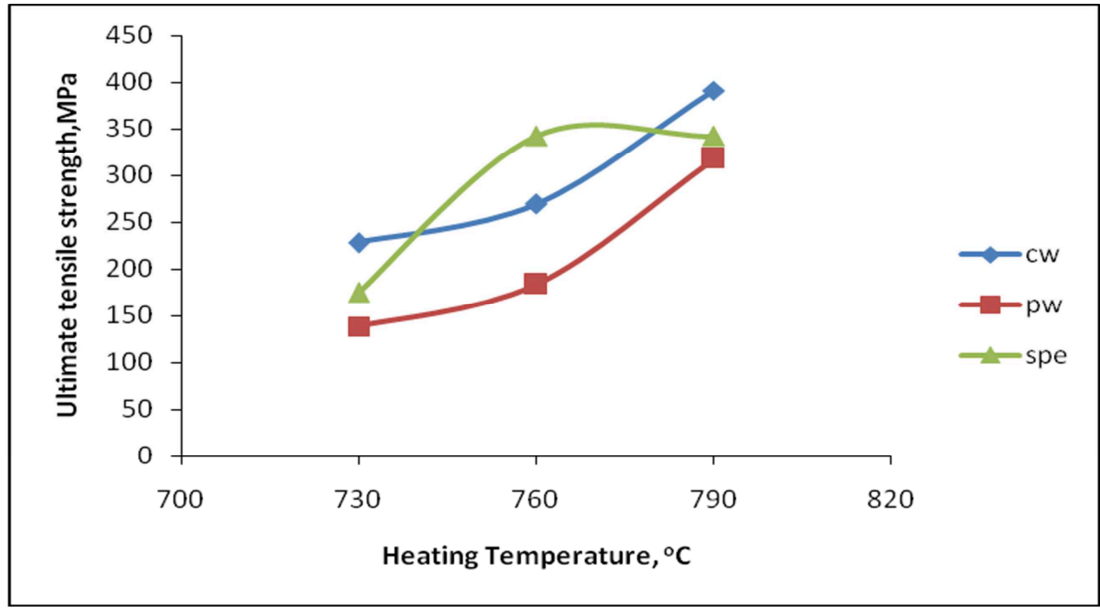

Fig. 7: Ultimate tensile strength against heating temperature at 45 mins soaking time.

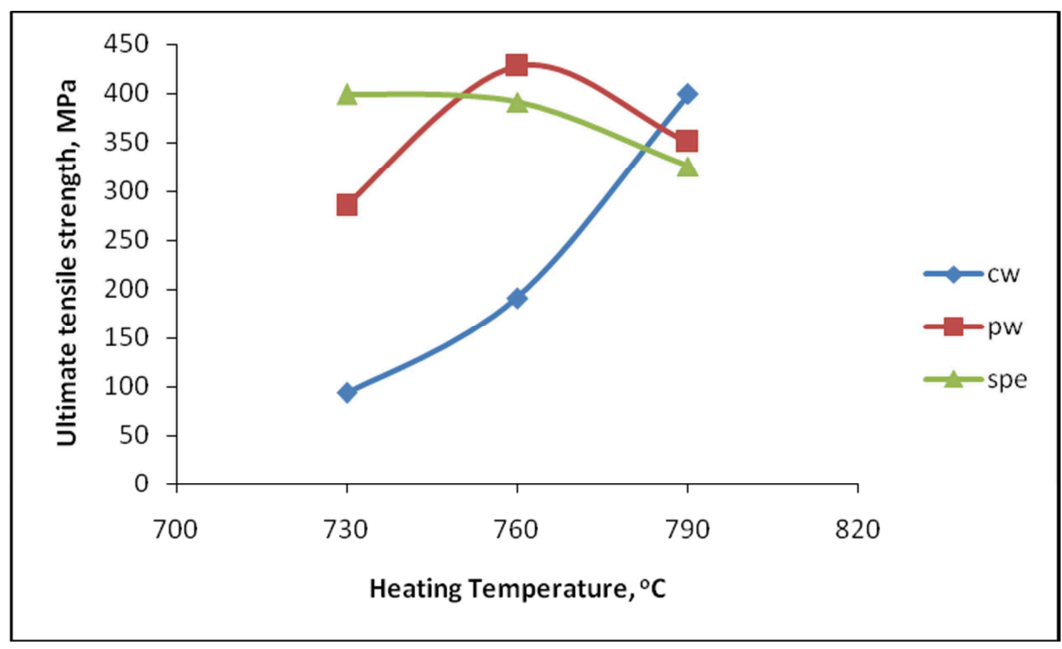

Fig. 8: Ultimate tensile strength against heating temperature at 60 mins soaking time. 


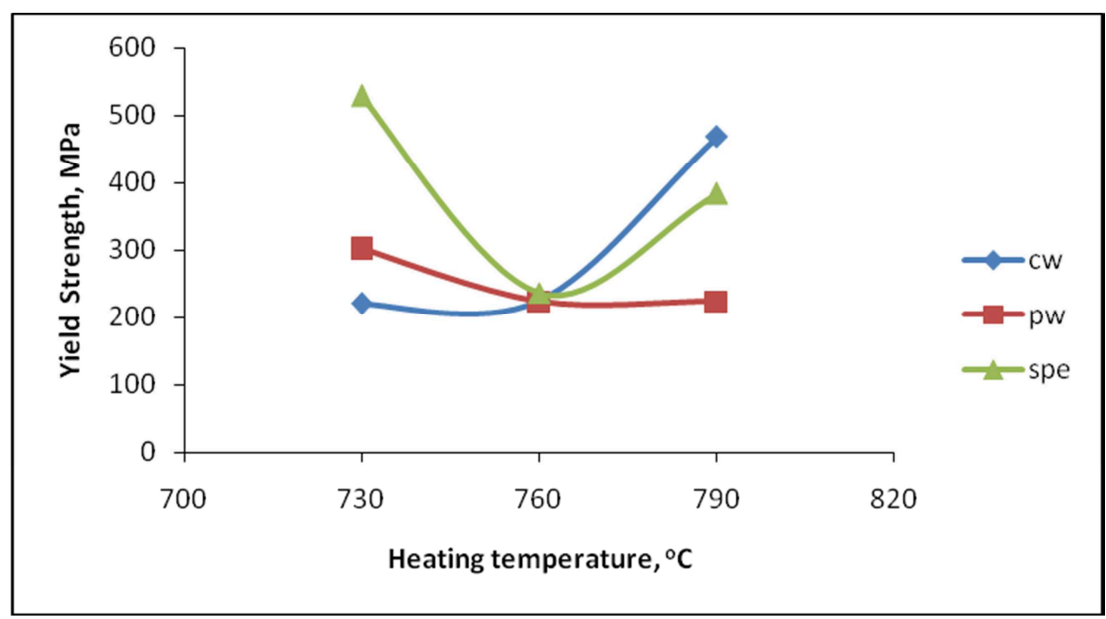

Fig. 9: Yield strength against heating temperature at 30 mins soaking time.

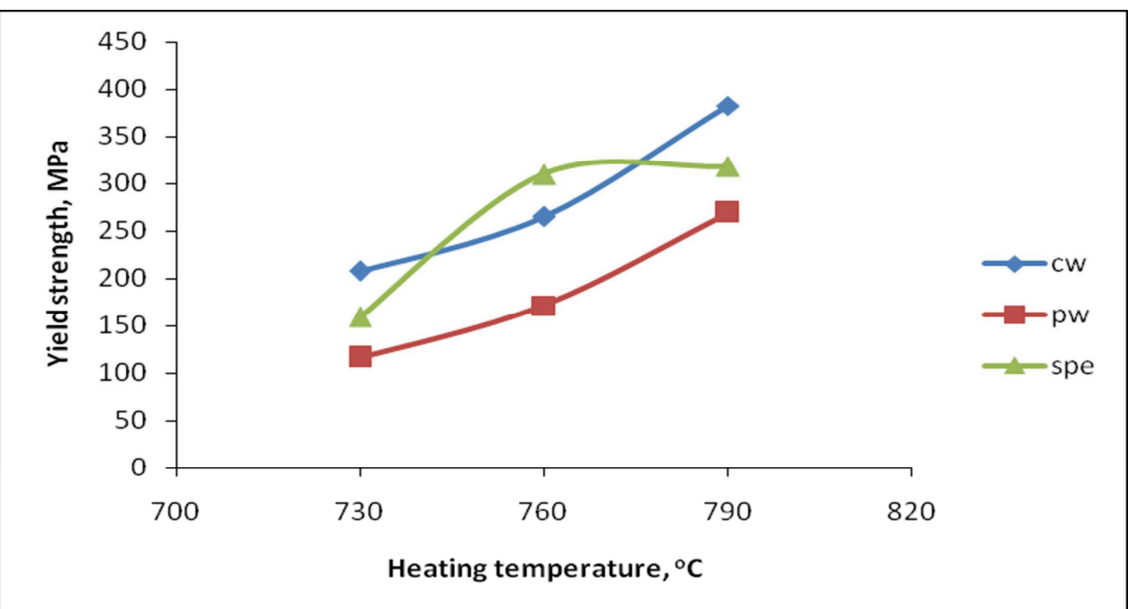

Fig. 10: Yield strength against heating temperature at 45 mins soaking time.

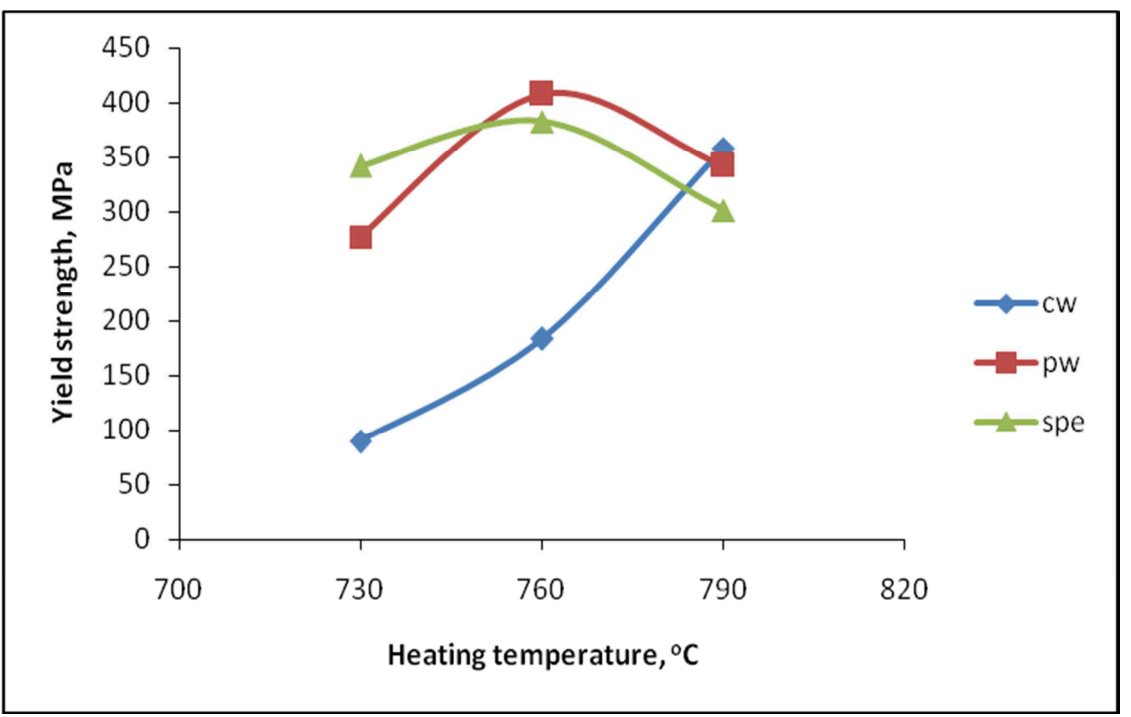

Fig. 11: Yield strength against heating temperature at 60 mins soaking time. 


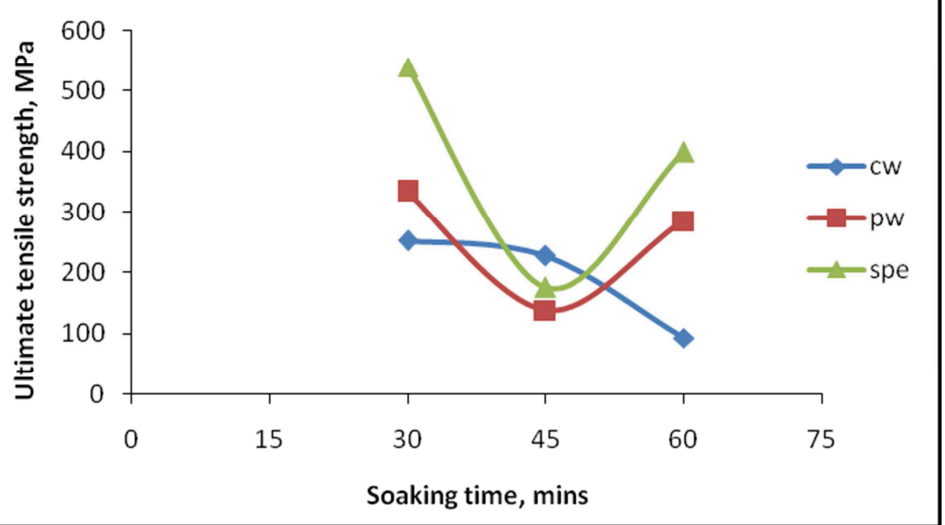

Fig. 12: Ultimate tensile strength against soaking time at $730^{\circ} \mathrm{C}$ heating temperature.

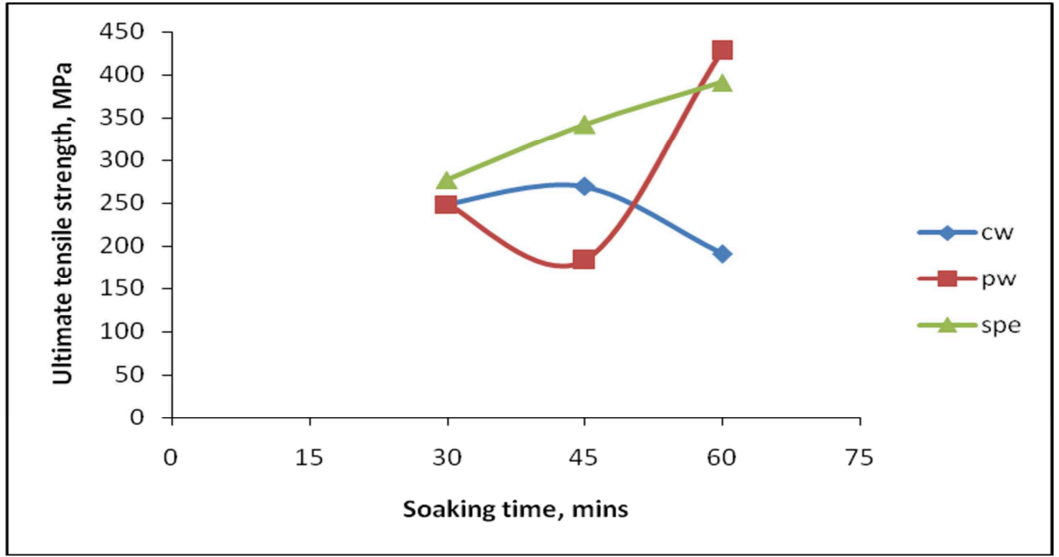

Fig. 13: Ultimate tensile strength against soaking time at $760^{\circ} \mathrm{C}$ heating temperature.

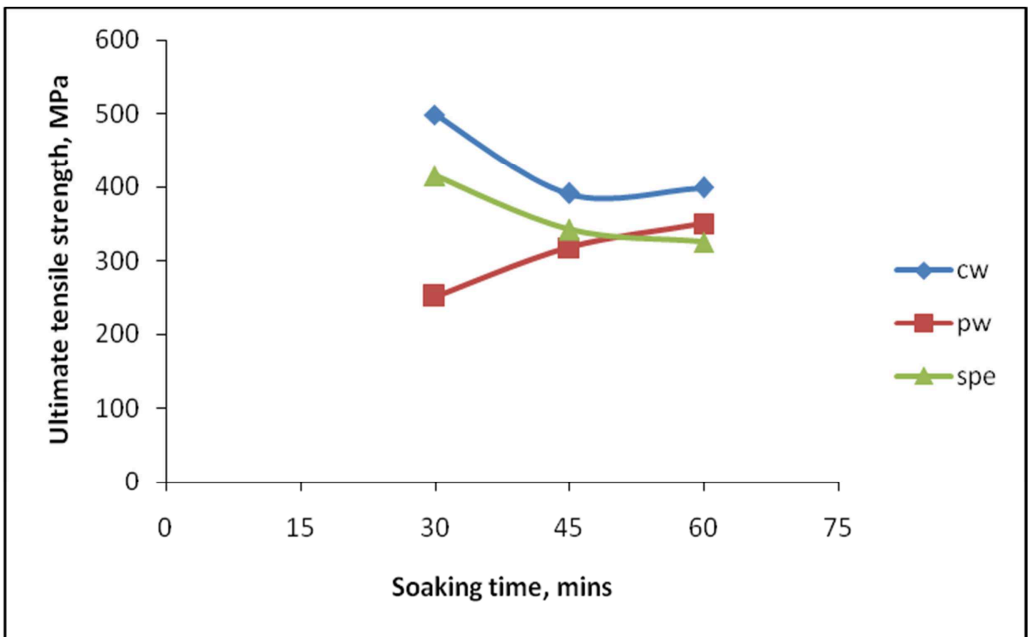

Fig. 14: Ultimate tensile strength against soaking time at $790^{\circ} \mathrm{C}$ heating temperature.

\section{Conclusions}

Coconut water, pap water and spent engine oil which could be considered as waste substances have been used as quenching media in order to improve the mechanical properties of medium carbon steel in this study. Medium carbon steel could be hardened when quenched in the various media used. Increase in heating temperature could increase the hardness properties of medium carbon steel when quenched in these media. The yield and ultimate tensile strengths of the samples quenched in these media were better than the normalized as-received sample. Hence, waste substances such as the coconut water, pap water and spent engine oil are recommended to be used as quenching media for the improvement of the properties of medium carbon steel especially for construction purposes. 


\section{Acknowledgements}

Authors appreciate Engr. Olabamiji T.S for using his laboratory (Strength of Material Lab of Landmark University) for this research work. Also we wish to appreciate the University for providing enabling environment in carrying out this research.

\section{References}

[1] B. Sanmbo, E. David, A. Samson and B. Olatunde, Challenges of producing quality construction steel bars in West Africa: Case-study of Nigeria steel industry, Journal of mineral and materials characterization \& engineering. 8(2009) 283-292.

[2] A. N Ede, Building collapse in Nigeria: The Trend of Casualties in the Last Decade (20002010), International Journal of Civil \& Environmental Engineering. 10 (2010) 32-42.

[3] A. G. F Alabi, Report on infrastructure decay in Kwara State: A study undertaken on behalf of the Nigerian Society of Engineers (NSE), Ilorin branch and submitted to the national headquarters of NSE Abuja, Working paper. (2009) 1-10.

[4] A. G. F Alabi and L. I Onyeji, Analysis and Comparative Assessment of Locally Produced Reinforcing Steel Bars for Structural Purposes, USEP: Journal of Research in Civil Engineering. 7 (2010) 49-60.

[5] A.G.F Alabi and R. A Yahaya, Comparative Assessment of Some Commercial Steel Bars with Standards, Journal of Research Information in Civil Engineering (RICE). 9(1) (2012) 073 - 083. Website: www.usep-rice.com, ISSN 0189-8787.

[6] J. K Odusote and A.A Adeleke, Analysis of Properties of Reinforcing SteelBars: Case Study of Collapsed Buildings in Lagos, Nigeria, Applied Mechanics \& Materials Journals. 204-208 (2012) 3052-3056.

[7] A.A Adeleke and J.K Odusote, Evaluation of Mechanical Properties of Reinforcing Steel Bars from Collapsed Buildings Sites, Journal of Failure Analysis and Prevention, 16 (2013).

[8] C. Arum, Verification of Properties of concrete Reinforcement Bars: Nigeria as Case Study, Indoor Built Environment. 17( 4)(2008) 370-376.

[9] J.K Odusote, T.K Ajiboye, and A.B Rabiu, Evaluation of mechanical properties of medium carbon steel quenched in water and oil, AU Journal of Technology. 15(4) (2012) 218-224.

[10] M. Dauda, L. S Kuburi, D. O Obada, and R. I Mustapha, Effects of various quenching media on mechanical properties of annealed $0.509 \mathrm{wt} \% \mathrm{C}-0.178 \mathrm{wt} \% \mathrm{Mn}$, Nigerian Journal of Technology. 34(3) (2015) 506-512.

[11] A. A Adediran, S. Aribo, and M. O. H Amuda, Mechanical properties of dual phase steel quenched in bitumen medium, Leonardo Electronic Journal of Practices and Technologies. 26(2015) 1-16.

[12] BSI Standard (2016): available online at http://www.jentayuventures.com (Date accessed: 2.08.2016.)

[13] M. A Filippow, M.A Gerver'er, Y. V Khudorozhkw and V.V Legchito, Influence of the quenching temperature on the phase composition of structure and wear resistance of 150XHM steel, Steel in translation, ISSN 0967-0912, 43 (11) (2012) 720-723.

[14] V. Leonidov, E. Y Nikitenko and I.D Zaitzeva, The effect quenching temperature on properties and structure of die-steel $4 \mathrm{KmM} 2 \mathrm{Fch}$, Institute of casting, Academy of Science of the Ukraine SSR, Translated from metallovedenic i Termicheskaya obrabotka metallove, 7 (1987) 45-47. 
[15] T. Vivek, P. Adarsh, M. Zuber, and I. B Chardreshekar, Production of quench severity of various quenching media based on hardness and microstructure studies, International Journal of Innovative Res. Adv, Eng. 1(3) (2013) 20-26.

[16] R. R Singh, A. Gaikwad, S. S Singh, and V. P Singh, Comparison of mechanical properties of medium carbon steel with dual phase steel, International Journal of Mechanical Engineering. 4(4) (2015) 1-8

[17] J. K Odusote, J. A Adebisi, M.A Abegunde and A. A Adeleke, Effect of Heat Treatment on the Mechanical Properties of Reinforced Steel Bar, Proceeding of 2013 Annual National Conference and Technology Exhibition of Nigeria Society of Engineers, Mettalurgical and Materials Division (Port Harcourt 2013) Port Harcourt, River State, (2013)10-16. 